\title{
Genitourinary Route of Administration
}

National Cancer Institute

\section{Source}

National Cancer Institute. Genitourinary Route of Administration. NCI Thesaurus. Code C38214.

Route of drug administration through the irrigation of organs pertaining to the genital and urinary systems. 